\title{
Resolvin E1 inhibits dendritic cell migration in the skin and attenuates contact hypersensitivity responses
}

\section{AUTHOR(S):}

Sawada, Yu; Honda, Tetsuya; Hanakawa, Sho; Nakamizo, Satoshi; Murata, Teruasa; Ueharaguchi-Tanada, Yuri; Ono, Sachiko; ... Nakamura, Motonobu; Miyachi, Yoshiki; Kabashima, Kenji

\section{CITATION:}

Sawada, Yu ... [et al]. Resolvin El inhibits dendritic cell migration in the skin and attenuates contact hypersensitivity responses. Journal of Experimental Medicine 2015, 212(11): 1921-1930

\section{ISSUE DATE:}

2015-10-05

\section{URL:}

http://hdl.handle.net/2433/209901

\section{RIGHT:}

(c) 2015 Sawada et al. This article is distributed under the terms of an Attribution-Noncommercial-Share Alike-No Mirror Sites license for the first six months after the publication date (see http://www.rupress.org/terms). After six months it is available under a Creative Commons License (Attribution-Noncommercial-Share Alike 3.0 Unported license, as described at http://creativecommons.org/licenses/by-nc-sa/3.0/) 


\section{Resolvin E1 inhibits dendritic cell migration in the skin and attenuates contact hypersensitivity responses}

\author{
Yu Sawada, ${ }^{1,3}$ Tetsuya Honda, ${ }^{1,2}$ Sho Hanakawa, ${ }^{1}$ Satoshi Nakamizo, ${ }^{1}$ \\ Teruasa Murata, ${ }^{1}$ Yuri Ueharaguchi-Tanada, ${ }^{1}$ Sachiko Ono, ${ }^{1}$ Wataru Amano, ${ }^{1}$ \\ Saeko Nakajima, ${ }^{1}$ Gyohei Egawa, ${ }^{1}$ Hideaki Tanizaki, ${ }^{1}$ Atsushi Otsuka, ${ }^{1}$ \\ Akihiko Kitoh, ${ }^{1}$ Teruki Dainichi, ${ }^{1}$ Narihito Ogawa, ${ }^{4}$ Yuichi Kobayashi, ${ }^{4}$ \\ Takehiko Yokomizo, ${ }^{5}$ Makoto Arita, ${ }^{6,7,8}$ Motonobu Nakamura, ${ }^{3}$ \\ Yoshiki Miyachi, ${ }^{1}$ and Kenji Kabashima ${ }^{1,6}$ \\ 'Department of Dermatology and ${ }^{2}$ Center for Innovation in Immunoregulative Technology and Therapeutics, Kyoto University \\ Graduate School of Medicine, Sakyo-ku, Kyoto 606-8501, Japan \\ ${ }^{3}$ Department of Dermatology, University of Occupational and Environmental Health, Kitakyushu, Fukuoka 807-8555, Japan \\ ${ }^{4}$ Department of Biomolecular Engineering, Graduate School of Bioscience and Biotechnology, Tokyo Institute of Technology, \\ Meguro-ku, Tokyo 152-8550, Japan \\ ${ }^{5}$ Department of Biochemistry, Juntendo University School of Medicine, Bunkyo-ku, Tokyo 113-8421, Japan \\ ${ }^{6}$ PRESTO, Japan Science and Technology Agency, Chiyoda-ku, Tokyo 102-0076, Japan \\ 'Laboratory for Metabolomics, RIKEN Center for Integrative Medical Sciences, Yokohama, Kanagawa 230-0045, Japan \\ ${ }^{8}$ Graduate School of Medical Life Science, Yokohama City University, Kanazawa-ku, Yokohama 236-0027, Japan
}

Resolvin E1 (RvE1) is a lipid mediator derived from $\omega 3$ polyunsaturated fatty acids that exerts potent antiinflammatory roles in several murine models. The antiinflammatory mechanism of RvE1 in acquired immune responses has been attributed to attenuation of cytokine production by dendritic cells (DCs). In this study, we newly investigated the effect of RvE1 on DC motility using two-photon microscopy in a contact hypersensitivity (CHS) model and found that RvE1 impaired DC motility in the skin. In addition, RvE1 attenuated T cell priming in the draining lymph nodes and effector T cell activation in the skin, which led to the reduced skin inflammation in CHS. In contrast, leukotriene B4 (LTB4) induced actin filament reorganization in DCs and increased DC motility by activating Cdc42 and Rac1 via BLT1, which was abrogated by RvE1. Collectively, our results suggest that RvE1 attenuates cutaneous acquired immune responses by inhibiting cutaneous DC motility, possibly through LTB4-BLT1 signaling blockade.

\section{CORRESPONDENCE}

Tetsuya Honda:

hontetsu@kuhp.kyoto-u.ac.jp

$\mathrm{OR}$

Kenji Kabashima:

kaba@kuhp.kyoto-u.ac.jp

Abbreviation used: Ab, antibody; CHS, contact hypersensitivity; dLN, draining LN; DNBS, dinitrobenzene sulfonic acid; DNFB, 2,4-dinitrofluorobenzene; MFI, mean fluorescence intensity; PUFA, polyunsaturated fatty acid.
Following the well-known epidemiological study conducted in Northwest Greenland in the 1970s (Dyerberg et al., 1978), several clinical assessments have indicated that a diet rich in $\omega 3$ polyunsaturated fatty acids (PUFAs) has beneficial effects in various inflammatory diseases, including asthma, psoriasis, inflammatory bowel diseases, and rheumatoid arthritis (Horrobin, 1987). Although it remains unclear how $\omega 3$ PUFAs exert such antiinflammatory effects, recent studies have identified several derivatives of $\omega 3$ PUFAs that possess strong antiinflammatory effects (Serhan et al., 2008; Tull et al., 2009). Resolvin E1 (RvE1) is one such antiinflammatory lipid mediator.

$\mathrm{RvE}_{\mathrm{v} 1}$ is known to exert its actions through two receptors, BLT1 and ChemR23 (Arita et al.,
2007). RvE1 binds to BLT1, a G protein-coupled receptor for leukotriene B4 (LTB4), and inhibits BLT1 signals (Arita et al., 2007). In addition, RvE1 exhibits an agonistic activity toward ChemR23 (Arita et al., 2007), a G protein-coupled receptor for chemerin. The antiinflammatory effects of RvE1 have been demonstrated in acute innate immune inflammation, such as peritonitis (Arita et al., 2007) and colitis (Arita et al., 2005b). In these models, RvE1 exerted its antiinflammatory effects by inhibiting neutrophil infiltration

\footnotetext{
2015 Sawada et al. This article is distributed under the terms of an AttributionNoncommercial-Share Alike-No Mirror Sites license for the first six months after the publication date (see http://www.rupress.org/terms). After six months it is available under a Creative Commons License (Attribution-NoncommercialShare Alike 3.0 Unported license, as described at http://creativecommons.org/
} licenses/by-nc-sa/3.0/
The Rockefeller University Press $\$ 30.00$ J. Exp. Med. 2015 Vol. 212 No. $11 \quad 1921-1930$ www.jem.org/cgi/doi/10.1084/jem.20150381
Supplemental Material can be found at:
http://jem.rupress.org/content/suppl/2015/10/01/jem.20150381.DC1.htm 1921 


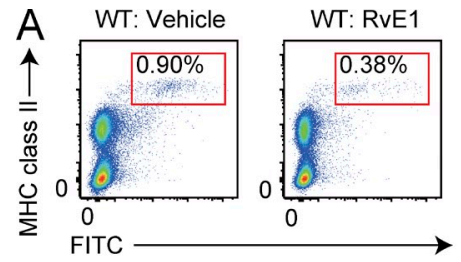

B $\mathrm{FITC}^{+} \mathrm{MHC}$ class II+ $\quad$ C $\mathrm{FITC}^{+} \mathrm{MHC}^{+}$class $\mathrm{I}^{+}$
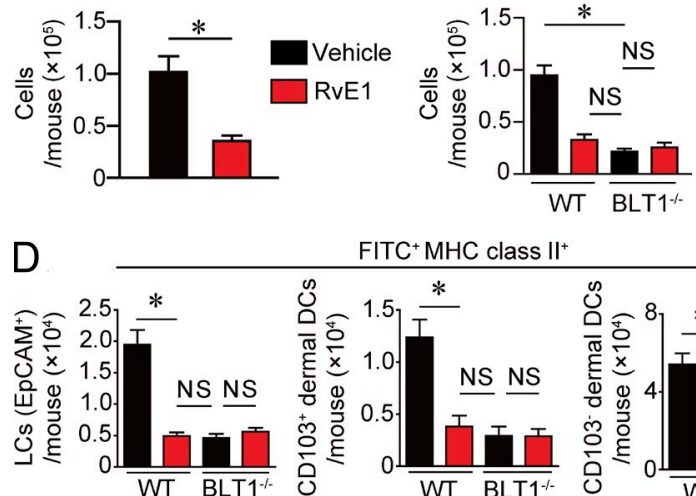

FITC ${ }^{+} \mathrm{MHC}$ class $\mathrm{I}^{+}$
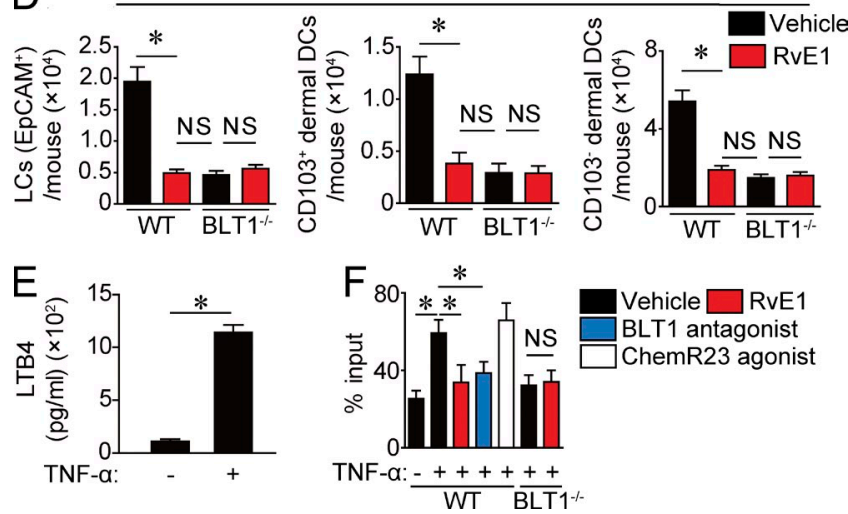

Figure 1. Inhibition of DC migration in the inflammatory state by RvE1 or a BLT1 antagonist. (A-C) FITC-induced DC migration assay. (A) Representative FACS plots of FITC+ $\mathrm{MHC}$ class $\mathrm{Il}^{+}$cells in dLNs. Mice were treated with either vehicle or RvE1 (200 ng/mouse) 30 min before and $1 \mathrm{~d}$ after FITC application. LN cell suspensions were prepared from $\mathrm{dLNs} 48 \mathrm{~h}$ after FITC application and subjected to a flow cytometric analysis. (B) Number of migrated FITC $\mathrm{MHC}^{+}$class $\mathrm{II}^{+} \mathrm{DCs}$ in $\mathrm{dLNs}(n=4)$. (C) Number of migrated DCs in WT and BLT1-deficient mice $(n=3)$. (D) Number of migrated FITC-positive Langerhans cells (EpCAM+), CD 103+ dermal DCs, and CD103- dermal DCs in WT and BLT1-deficient mice $(n=3)$. (E) LTB4 production by BMDCs after TNF stimulation. BMDCs were stimulated with $100 \mathrm{ng} / \mathrm{ml}$ TNF for $12 \mathrm{~h}$, and the LTB4 concentration in culture supernatant was measured by ELISA. (F) Transwell migration assay. WT or BLT1-deficient BMDCs pretreated with 100 nM RvE1, 10 nM BLT1 antagonist, or $100 \mu \mathrm{M}$ ChemR23 agonist were incubated with or without $100 \mathrm{ng} / \mathrm{ml}$ TNF and examined for chemotaxis to $100 \mathrm{ng} / \mathrm{ml} \mathrm{CCL21.} \mathrm{The}$ migrated BMDC number was evaluated by flow cytometry. Data are presented as the percentage of migrated DCs to total input. Results are expressed as the mean \pm SEM. All p-values were obtained by Student's $t$ test: ${ }^{*}, \mathrm{P}<0.05$. All data are representative of five independent experiments with reproducible results.

into the inflammatory foci through a blockade of LTB4-BLT1 signaling in neutrophils (Haas-Stapleton et al., 2007). In contrast, few studies have been conducted on the effect of RvE1 on acquired immune responses, in which DCs and T cells play major roles in the development. In these studies, the attenuated cytokine production, such as IL-12 and IL-23, from DCs is considered as the major mechanism by which RvE1 exerts the antiinflammatory effects (Arita et al., 2005a; Haworth et al.,
2008). However, the effect of RvE1 on DC motility has not been investigated in the context of acquired immunity.

In the peripheral tissues such as the skin, DCs migrate in an amoeboid movement that requires actin polymerization via activation of the Rho family of small GTPases, such as Cdc42, Rac, and Rho A (Lämmermann and Germain, 2014). In acquired immunity such as contact hypersensitivity (CHS), upon uptake of foreign antigens, DCs migrate to the draining LNs (dLNs) via lymphatic vessels to establish sensitization by inducing the antigen-specific $\mathrm{T}$ cell differentiation (Honda et al., 2013). In elicitation, DC migration to form DC-T cell clustering is required for efficient antigen presentation in situ (Natsuaki et al., 2014). Thus, active DC motility is an essential factor for acquired immunity.

In this study, we investigated the effects and underlying mechanisms of RvE1 on DC motility using a CHS model, which is a prototype of delayed-type hypersensitivity in the skin mediated by IFN- $\gamma$ (Mori et al., 2008; Honda et al., 2013). RvE1 inhibited cutaneous DC migration into the dLNs and suppressed antigen-specific $T$ cell induction in the sensitization phase. In addition, live imaging analysis revealed that RvE1 inhibited cutaneous DC motility and cluster formation in the skin, which subsequently attenuated activation of effector T cells in the skin in the elicitation phase of CHS Intriguingly, LTB4 induced actin filament reorganization in DCs and increased DC motility by activating Cdc42 and Rac1 via BLT1, which was abrogated by RvE1. These results suggest that RvE1 exerts its antiinflammatory effects in cutaneous acquired immunity by inhibiting DC motility, possibly through an LTB4-BLT1 signaling blockade.

\section{RESULTS}

\section{RvE1 inhibits DC migration from skin to dLNs}

To examine the effect of RvE1 on cutaneous DC migration to dLNs, we used an FITC-induced cutaneous DC migration assay in the presence or absence of RvE1. Mice treated with RvE1 exhibited a significantly reduced number of migrated DCs in the dLNs, suggesting that RvE1 regulates cutaneous DC migration (Fig. 1,A and B). We next sought to identify the receptors through which $\mathrm{RvE} 1$ exerts the inhibitory effects on cutaneous DC migration. $\mathrm{RvE} 1$ is known to elicit its functions via two receptors, BLT1 and ChemR23 (Arita et al., 2007). We first examined the involvement of ChemR23 signaling on cutaneous DC migration using chemerin, a ChemR23 agonist, with two different doses (500 ng/body and $5 \mu \mathrm{g} /$ body $)$ according to previous studies (Luangsay et al., 2009; Lin et al., 2014). However, the ChemR 23 agonist did not affect cutaneous DC migration in these conditions (not depicted).

Then, we examined the involvement of BLT1 in the effects of RvE1 using BLT1-deficient mice. BLT1-deficient mice exhibited impaired cutaneous DC migration, which was similar to the extent of RvE1-treated WT mice (Fig. 1 C). No additional inhibitory effect of RvE1 on DC migration was observed in BLT1-deficient mice (Fig. 1 C), suggesting the involvement of BLT1 in the inhibitory effect of RvE1. 
Because there are at least three DC subsets in the skin (Langerhans cells, CD103+ dermal DCs [Langerin-positive dermal DCs], and CD103- dermal DCs [Langerin-negative dermal DCs]; Honda et al., 2010), we examined the effect of RvE1 on each DC subset in an FITC-induced cutaneous DC migration assay. We found that RvE1 inhibited the migration of each DC subset similarly (Fig. 1 D). These results indicate that the effect of RvE1 may not be restricted to a particular DC subset.

To ascertain the aforementioned findings, we generated BMDCs and compared the effects of RvE1, BLT1 antagonist U-75302, and ChemR23 agonist chemerin on TNF-stimulated BMDC migration. First, we observed that BMDCs produced LTB4, which was significantly augmented by TNF stimulation (Fig. 1 E). The TNF-induced chemotaxis toward CC chemokine ligand 21 (CCL21) was significantly impaired by RvE1 and BLT1 antagonist treatment, but not by ChemR23 agonist treatment (Fig. 1 F). In addition, the attenuated chemotaxis in BLT1-deficient BMDCs was not further impaired by RvE1 treatment (Fig. 1 F). These results suggest that RvE1 regulates cutaneous DC migration through a blockade of autonomous LTB4-BLT1 signaling pathway.

\section{RvE1 suppresses the sensitization in CHS}

Next, we evaluated the impact of impaired DC migration by RvE1 on acquired cutaneous immune response using a CHS model. We first examined the effect of RvE1 in the sensitization phase of CHS because dermal DC migration to dLNs is an essential step for sensitization (Honda et al., 2013). WT mice treated with RvE1 exhibited a significantly reduced number of CD $44^{+} \mathrm{CD}_{2} \mathrm{~L}^{+}$central memory T cells and CD $44^{+}$ $\mathrm{CD} 2 \mathrm{~L}^{-}$effector memory $\mathrm{T}$ cells in dLNs after $0.5 \% 2,4-$ dinitrofluorobenzene (DNFB) application (Fig. 2A). In addition, antigen-specific $\mathrm{T}$ cell proliferation and IFN- $\gamma$ production by dLN cells were significantly reduced in RvE1-treated WT mice (Fig. 2, B and C). Consistently, RvE1 significantly decreased the ear swelling response, an indicator of skin inflammation, in WT mice (Fig. 2 D).

In contrast, BLT1-deficient mice exhibited a significantly reduced ear swelling response similar to that of $\mathrm{RvE} 1$-treated WT mice. RvE1 treatment did not impair the CHS response further in BLT1-deficient mice (Fig. 2 D), providing evidence that RvE1 regulates cutaneous DC migration and subsequent sensitization in CHS, possibly through a blockade of LTB4-BLT1 signaling.

\section{RvE1 inhibits BLT1-induced cutaneous DC migration in the steady state}

Cutaneous DCs constantly migrate to dLNs in both the inflammatory state (e.g., FITC-induced DC migration) and the noninflammatory steady state. To examine whether RvE1 inhibits DC migration in the steady state, we applied a photolabeling system using Kaede transgenic mice. Kaede is a photoconvertible fluorescence protein that changes from green (Kaede-green) to red (Kaede-red) upon exposure to violet light (Ando et al., 2002). This system allows us to photolabel
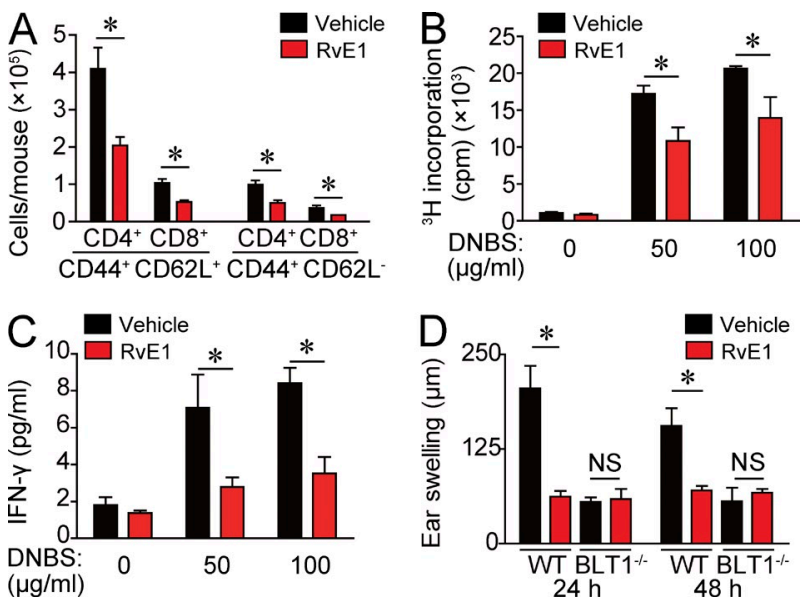

Figure 2. Decreased CHS response to DNFB by RvE1. (A) Flow cytometric analysis for $\mathrm{dLN}$ cell composition $5 \mathrm{~d}$ after $0.5 \%$ DNFB application in the presence or absence of RvE1 treatment. Bars indicate the numbers in each cell subset $(n=4)$. (B) $\left[{ }^{3} \mathrm{H}\right]$ thymidine incorporation by $\mathrm{dLN}$ cells after DNBS stimulation. Cell suspensions of dLNs from DNFB-sensitized mice were cultured for $3 \mathrm{~d}$ with or without 50 or $100 \mu \mathrm{g} / \mathrm{ml}$ DNBS. Cells were pulsed with $0.5 \mu \mathrm{Ci}\left[{ }^{3} \mathrm{H}\right]$ thymidine for the last $24 \mathrm{~h}$ and subjected to liquid scintillation counting. (C) ELISA analysis for measuring IFN- $\gamma$ in the culture medium $48 \mathrm{~h}$ after the culture. (D) Ear thickness change at 24 and $48 \mathrm{~h}$ after the challenge with 0.3\% DNFB. WT and BLT1-deficient mice were treated with or without RvE1 ( $200 \mathrm{ng} /$ mouse) $1 \mathrm{~d}$ and 30 min before sensitization $(n=4)$. Results are expressed as the mean \pm SEM. All p-values were obtained by Student's $t$ test: ${ }^{*}, P<0.05$. All data are representative of three independent experiments with reproducible results.

the cells without tissue damage and inflammation (Tomura et al., 2010).

The abdominal skin of Kaede transgenic mice was exposed to innocuous violet light (Fig. 3 A) for labeling skin cells as red by photoconversion. The number of migrated cutaneous DCs (Kaede-red DCs) from the skin to dLNs was significantly reduced in RvE1- or BLT1 antagonist-treated mice than that in vehicle-treated mice (Fig. 3, B and C). The motility of the three skin DC subsets was similarly affected by RvE1 or the BLT1 antagonist (Fig. 3 D). These results indicate that LTB4-BLT1 signaling regulates cutaneous constitutive DC migration to dLNs in the steady state skin as in the hapten-induced inflammatory skin.

\section{LTB4-BLT1 signaling is essential for cutaneous DC motility}

Next, we examined the in vivo mechanisms by which RvE1 regulates cutaneous DC migration to dLNs. CD11c-YFP mice were used for the visualization of cutaneous DCs (Lindquist et al., 2004), and the ear skin of CD11c-YFP mice were subjected to two-photon microscopy observation for intravital imaging of cutaneous DCs (Honda et al., 2014; Natsuaki et al., 2014). $1 \mathrm{~h}$ after the initiation of the observation, mice were treated with vehicle, RvE1, or a BLT1 antagonist, and DC morphology and motility were observed for another 3 h. Before RvE1 and/or BLT1 antagonist treatment, cutaneous DCs exhibited active motility with polarized morphology, filopodia- and lamellipodia-like structures at the leading edge, 
A
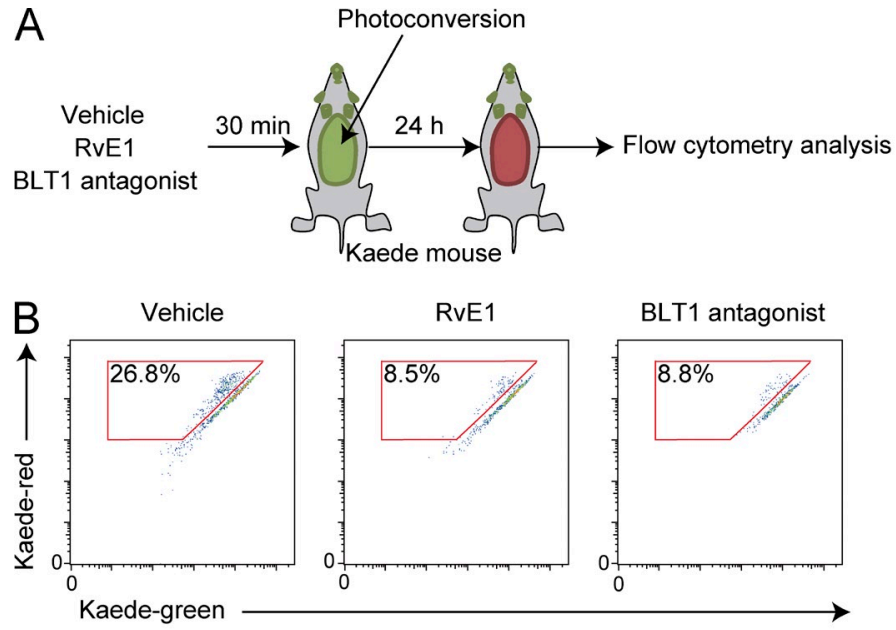

BLT1 antagonist
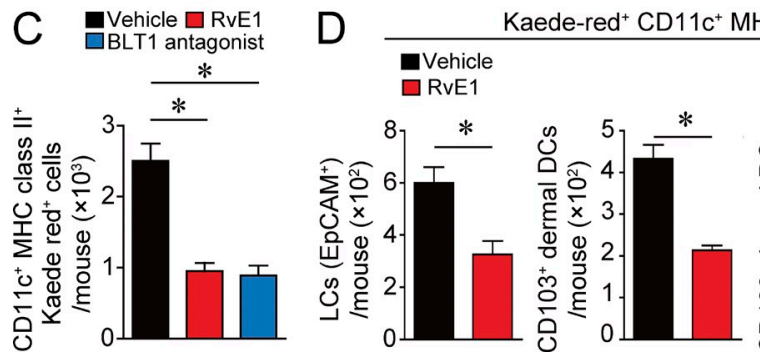

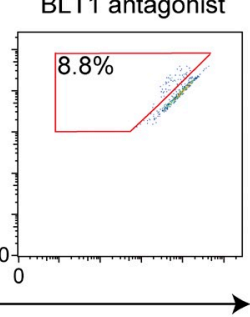

aede-red ${ }^{+}$CD11C $\mathrm{CHC}^{+}$class $\mathrm{II}^{+}$

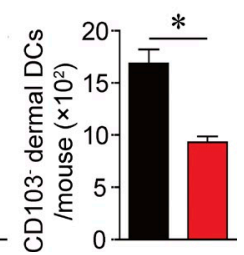

Figure 3. Inhibition of DC migration in the steady state by RvE1 or a BLT1 antagonist. (A) Schema of photoconversion. Kaede transgenic mice were treated with vehicle, RvE1 (200 ng/mouse), or a BLT1 antagonist (ONO-4057; 60 mg/ mouse). Then the shaved abdominal skin was irradiated with violet light (photoconversion) 30 min after the drug administration. $24 \mathrm{~h}$ after the photoconversion, the draining axillary and popliteal LNs were collected, stained with anti-CD11c and MHC class II mAbs, and subjected to flow cytometric analysis. (B) Representative FACS plots gated on $\mathrm{CD} 11 \mathrm{C}^{+} \mathrm{MHC}$ class $\mathrm{II}^{+}$cells in each condition. Numbers within the red squares indicate the percentage of migrated cells (Kaede-red cells) among total CD11 $\mathrm{C}^{+} \mathrm{MHC}$ class II+ cells. (C) Quantification of the Kaede-redpositive CD11 $\mathrm{c}^{+} \mathrm{MHC}$ class II+ cells in dLNs $(n=3)$. (D) The numbers of each DC subset $\left(E p C A M^{+}\right.$Langerhans cells, CD103+ dermal DCs, and CD103- dermal DCs among Kaede-red ${ }^{+} \mathrm{CD} 11 \mathrm{C}^{+}$ $\mathrm{MHC}$ class II+ cells in dLNs; $n=3$ ). Results are expressed as the mean \pm SEM. All $p$-values were obtained by Student's $t$ test: ${ }^{*}, \mathrm{P}<0.05$. All data are representative of three independent experiments with reproducible results. and a trailing uropod-like structure (Video 1). However, $\sim 30$ min after RvE1 and/or BLT1 antagonist treatment, DCs became round in shape and their motility gradually decreased (Fig. $4 \mathrm{~A}$ and Videos 2-4). Consistently, individual DC tracking showed significantly decreased displacement, mean track velocity, and straightness as a parameter of directionality in RvE1and/or BLT1 antagonist-treated mice (Fig. 4, B and C). No additional inhibitory effect of RvE1 and BLT1 antagonist on DC motility was observed (Fig. 4, B and C). Furthermore, we confirmed that RvE1 treatment did not affect DC viability in vivo and in vitro (not depicted), excluding the possibility of a toxic effect of RvE1.

Next, we evaluated the DC motility under an inflammatory condition. RvE1 and BLT1 antagonist exerted similar inhibitory effects on DC motility in the hapten-treated inflammatory skin (Fig. 4, D and E; and Videos 5-8). No additional inhibitory effect of RvE1 and BLT1 antagonist on DC motility under inflammatory conditions was observed (Fig. 4, $\mathrm{D}$ and E). To further clarify whether the loss of BLT1 signaling on DCs intrinsically impairs DC motility, we generated mixed BM chimeras using BM cells from WT mice (CD45.1 positive) and BLT1-deficient mice (CD45.2 positive). 2 mo after the reconstitution, mice were applied to an FITCinduced cutaneous DC migration assay, and the number of FITC $^{+}$migrated DCs in dLNs as well as the skin-resident DCs in steady-state were evaluated by flow cytometry. The migration ratio was calculated by dividing the number of FITC $^{+}$migrated DCs in the dLNs after FITC application (migrated DCs) by that of skin-resident DCs under steady states per square millimeter (skin-resident DCs) in WT and
BLT1-deficient DCs $(n=4)$. The migration ratio (migrated DCs/skin-resident DCs) was significantly higher in WT DCs $(0.0193 \pm 0.0024[$ mean $\pm \mathrm{SEM} ; n=4])$ than that in BLT1deficient DCs $(0.0048 \pm 0.0006[$ mean \pm SEM; $n=4])$. These findings strongly support that LTB4-BLT1 signaling is intrinsically essential for cutaneous DC motility and that RvE1 inhibits DC motility in the skin, possibly by antagonizing the LTB4-BLT1 signaling in both the steady and the inflammatory states.

\section{LTB4-BLT1 signaling mediates DC cluster formation in the skin}

The aforementioned results suggest that BLT1-dependent DC motility plays a key role in CHS during both the sensitization and elicitation phases because increased DC motility and subsequent DC cluster formation around the postcapillary venules after the hapten application are essential for effector $\mathrm{T}$ cell activation in the skin during the elicitation phase (Natsuaki et al., 2014). In light of this, we next evaluated the involvement of LTB4-BLT1 signaling in DC cluster formation. The ear skin was subjected to whole-mount staining with anti-MHC class II antibody (Ab) $24 \mathrm{~h}$ after $0.5 \%$ DNFB application, and the size and the number of DC clusters were evaluated. Although numerous large DC clusters were observed in vehicle-treated WT mice, both the number and the size of DC clusters were significantly reduced in RvE1- or BLT1 antagonist-treated WT mice and also vehicle-treated BLT1-deficient mice (Fig. 5, A and B). In addition, RvE1 treatment did not exhibit further inhibitory effects on DC cluster in BLT1-deficient mice (Fig. 5, A and B). 
A
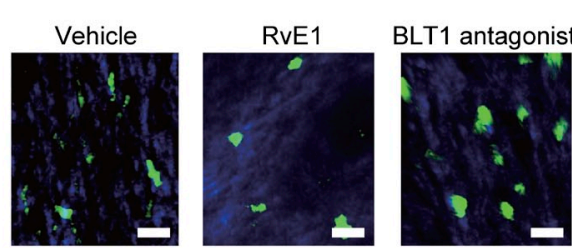

RvE1 plus

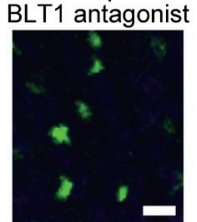

B
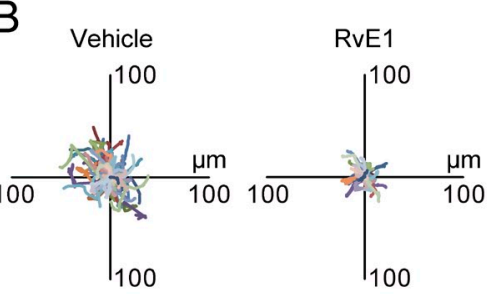

BLT1 antagonist

RvE1 plus BLT1 antagonist
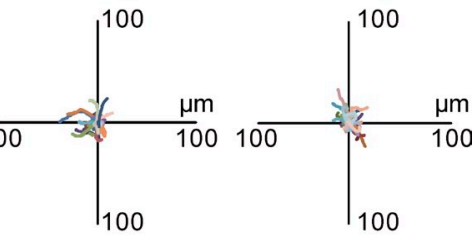

C
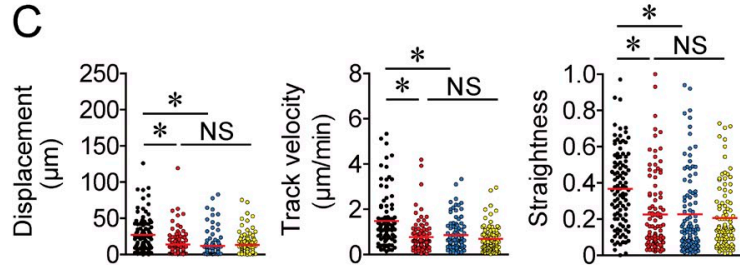

-Vehicle ORvE1

OBLT1 antagonist ORvE1 plus BLT1 antagonist

RvE1 plus
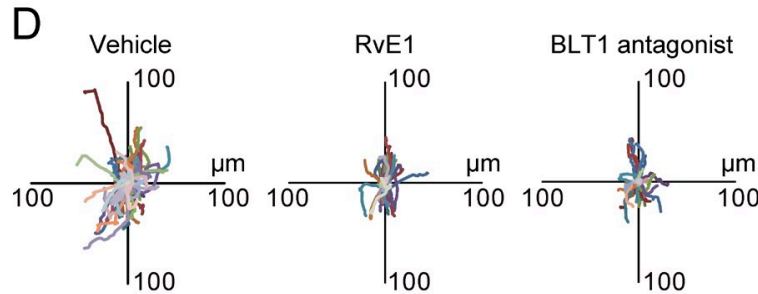

BLT1 antagonist
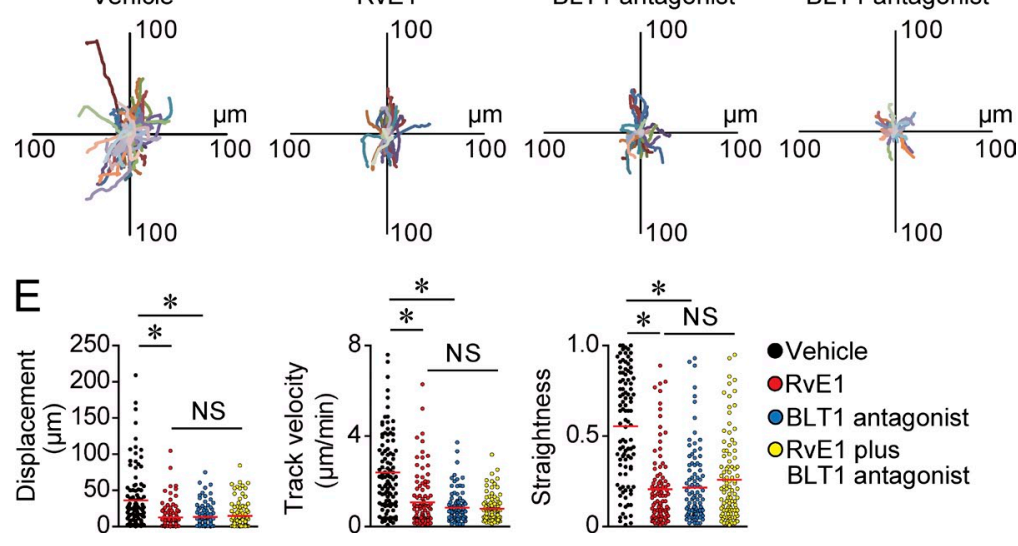

Figure 4. Inhibition of DC motility in the skin by BLT1 blockade. (A-C) Evaluation of cutaneous DC motility in the steady state skin. (A) Representative images of DC morphology. CD11c-YFP mice were treated with vehicle, RvE1 (200 $\mathrm{ng} /$ mouse), a BLT1 antagonist (ONO-4057; $60 \mu \mathrm{g} /$ mouse), or RvE1 (200 ng/mouse) plus a BLT1 antagonist ( $60 \mu \mathrm{g} /$ mouse), and DC morphology was examined $1 \mathrm{~h}$ after each drug treatment. Bars, $10 \mu \mathrm{m}$. (B) Overlay of 100 individual DC tracks. Superimposed 30-min tracks of 100 randomly selected CD11c-YFP+ cells $1 \mathrm{~h}$ after each drug treatment in the $\mathrm{X}-\mathrm{y}$ plane, setting the starting coordinates to the origin. (C) Comparison of CD11c-YFP+ cell displacement, track velocity, and straightness in B. Each symbol represents an individual cell. ( $D$ and E) Evaluation of cutaneous DC motility in the inflammatory state skin. (D) Overlay of 100 individual DC tracks plotted after aligning their starting positions. Ear skin of CD11c-YFP mice were applied with 0.5\% DNFB, and the mice were treated with vehicle, RvE1, a BLT1 antagonist, or RvE1 plus a BLT1 antagonist $3 \mathrm{~h}$ after the hapten application. Superimposed 30-min tracks of 100 randomly selected CD11c$\mathrm{YFP}^{+}$cells $1 \mathrm{~h}$ after each drug treatment in the $\mathrm{x}-\mathrm{y}$ plane. (E) Comparison of CD11c-YFP+ cell displacement, track velocity, and straightness in D. (C and E) Red horizontal lines indicate median values. All $p$-values were obtained by Welch's $t$ test: ${ }^{*}, P<0.05$. All data are representative of three independent experiments with reproducible results.
These results suggest that LTB4-BLT1 signaling facilitates DC cluster formation in the skin, which is abrogated by RvE1 treatment.

Next, we investigated whether the reduced DC cluster formation in RvE1-treated WT mice and BLT1-deficient mice led to impaired effector $\mathrm{T}$ cell activation in the skin. Administration of RvE1 or a BLT1 antagonist during the elicitation phase significantly suppressed the number of IFN- $\gamma$-producing $\mathrm{CD}^{+}$ $\mathrm{T}$ cells in the skin, accompanied by reduced ear swelling response (Fig. 5, C and D). The effect of RvE1 in combination with the BLT1 antagonist on the $\mathrm{CD}^{+} \mathrm{T}$ cell activation and the ear swelling response were similar to those induced by each drug treatment alone (Fig. 5, C and D).

We also sought to examine the physiological role of BLT1 in cutaneous DCs. To address this issue, we purified LN cells from DNFB-sensitized WT mice, which contained DNFBsensitized memory $\mathrm{T}$ cells, and transferred into either naive WT or BLT1-deficient mice. Then, the mice were challenged with DNFB on the ears, where WT-derived memory $\mathrm{T}$ cells interact with WT or BLT1-deficient DCs. BLT1-deficient recipient mice, which lacked BLT1 in skin DCs, exhibited fewer IFN- $\gamma$-producing $\mathrm{CD}^{+} \mathrm{T}$ cells in the skin and a reduced ear swelling response when compared with WT recipient mice (Fig. 5, E-G).

These results indicate that LTB4-BLT1 signaling facilitates DC motility to form DC cluster and memory $\mathrm{T}$ cell activation in the skin after hapten application. Although we could not completely exclude the possibility of the effect of RvE1 on other cells such as T cells and neutrophils, RvE1 seems to exert antiinflammatory roles in the elicitation phase of CHS, possibly through a blockade of LTB4-BLT1 signaling on DCs.

\section{LTB4 induces actin polymerization in DCs and promotes DC chemokinesis}

The actin cytoskeleton is essential to the regulation of cell formation, and the rates of polymerization/depolymerization 
A

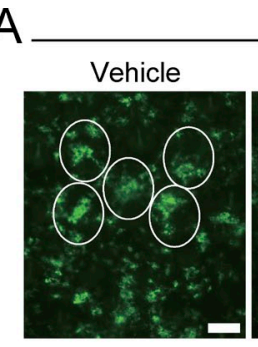

WT
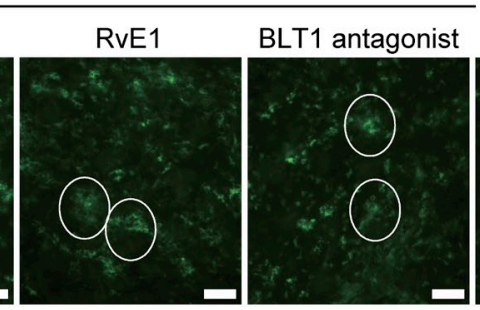

B Gehicle

$\square$ BLT1 antagonist

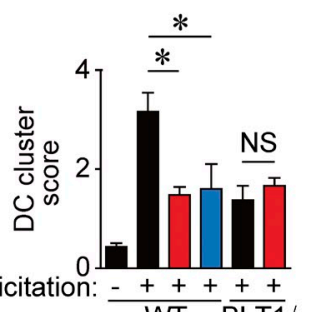

C Pehicle

BLT1 antagonist $\square$ BLT1 antagonist
$\square$ RvE1 plus BLT1 antagonist

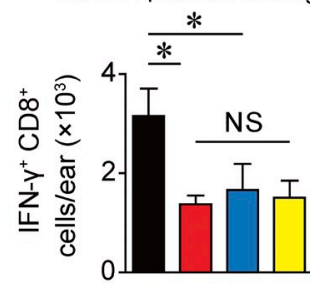

$\mathrm{BLT}^{-1-}$
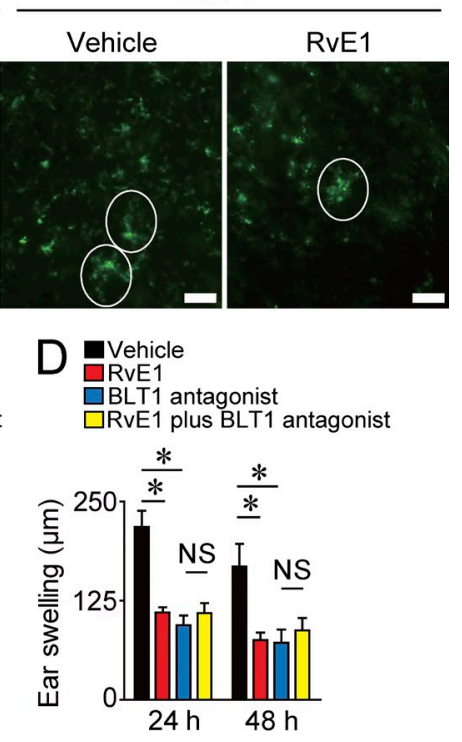

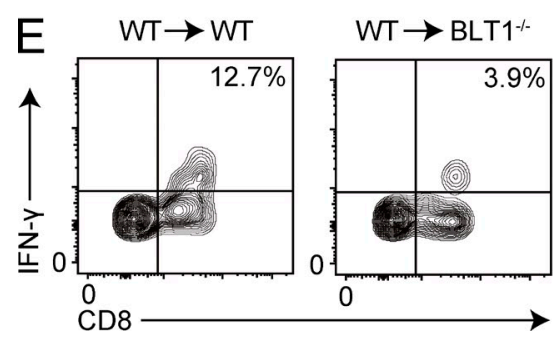

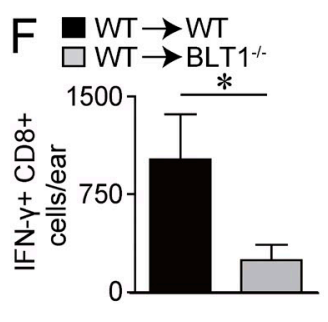

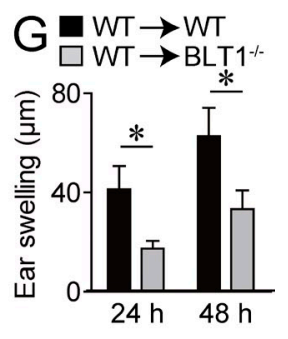

Figure 5. Attenuated DC cluster formation and effector $T$ cell activation in the skin by BLT1 blockade. (A) Representative images of the whole-mount staining of ear skin stained with anti-MHC class II mAb $24 \mathrm{~h}$ after DNFB application. Mice were treated with vehicle, RvE1, or a BLT1 antagonist 30 min before $0.5 \%$ DNFB application. White circles indicate DC cluster formation. Bars, $100 \mu \mathrm{m}$. (B) Quantification of DC cluster formation. Scores were assigned according to the size and the number of clusters $(n=4)$. (C) Number of IFN- $\gamma^{+} \mathrm{CD} 8^{+} \mathrm{T}$ cells per ear $18 \mathrm{~h}$ after $0.3 \%$ DNFB elicitation $(n=4)$. Mice were treated with vehicle, RvE1, a BLT1 antagonist, or RvE1 plus a BLT1 antagonist 30 min before the challenge $(n=3)$. (D) Ear thickness change at 24 and $48 \mathrm{~h}$ after the challenge. Mice were treated with vehicle, RvE1, a BLT1 antagonist, or RvE1 plus a BLT1 antagonist $30 \mathrm{~min}$ before the challenge $(n=3)$. (E) Representative FACS plots of IFN- $\gamma$ producing $\mathrm{CD} 8{ }^{+} \mathrm{T}$ cells in the skin $18 \mathrm{~h}$ after $0.5 \%$ DNFB elicitation. LN cells from DNFBsensitized WT mice were transferred into WT or BLT1-deficient mice. Recipient mice were challenged with 0.5\% DNFB after transfer $(n=4)$. Numbers in the top right quadrants indicate the percentage of IFN- $\gamma^{+} \mathrm{CD} 8^{+} \mathrm{T}$ cells in total $\mathrm{CD} 8^{+}$cells. (F) Number of IFN- $\gamma^{+} \mathrm{CD} 8^{+}$ T cells per ear $18 \mathrm{~h}$ after 0.5\% DNFB elicitation $(n=4)$. (G) Ear thickness change at 24 and $48 \mathrm{~h}$ after the challenge $(n=3)$. Results are expressed as the mean \pm SEM. All p-values were obtained by Student's $t$ test: ${ }^{*}, P<0.05$. All data are representative of five independent experiments with reproducible results.

Next, we examined the effect of LTB4 on Rho family protein activation in DCs because Rho family proteins, including Cdc42, Rac1, and Rho, play essential roles in actin polymerization (Lämmermann and Germain, 2014). Among the three Rho family proteins, LTB4 induced the conversion of the GDP-bound inactivated form of Cdc42 and Rac1 into their GTP-bound activated form in WT BMDCs, which was canceled by pretreatment with RvE1 or a BLT1 antagonist (Fig. 6, D and E). Consistently, LTB4-induced activation of Cdc42 and Rac1 was not observed in BLT1deficient BMDCs.

Finally, an in vitro transwell migration assay was performed to directly examine the effect of LTB4 on DC motility. LTB4 treatment significantly enhanced BMDC migration toward CCL21, a chemokine for cutaneous DC migration to dLNs (Förster et al., 1999), and chemokine (CXC motif) ligand 2 (CXCL2), a chemokine for DC cluster formation in the skin (Natsuaki et al., 2014), when compared with vehicle treated-BMDCs. These effects of LTB4 were abolished by pretreatment with RvE1 or the BLT1 antagonist (Fig. 6 F). 
$\underline{A}$

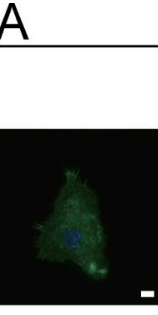

WT

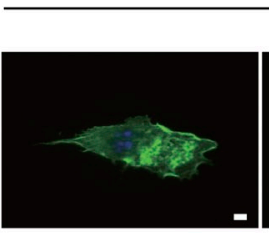

LTB4

LTB4
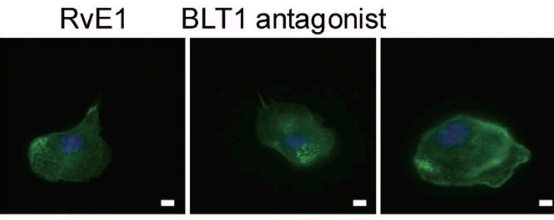

BLT1 ${ }^{-1-}$

B
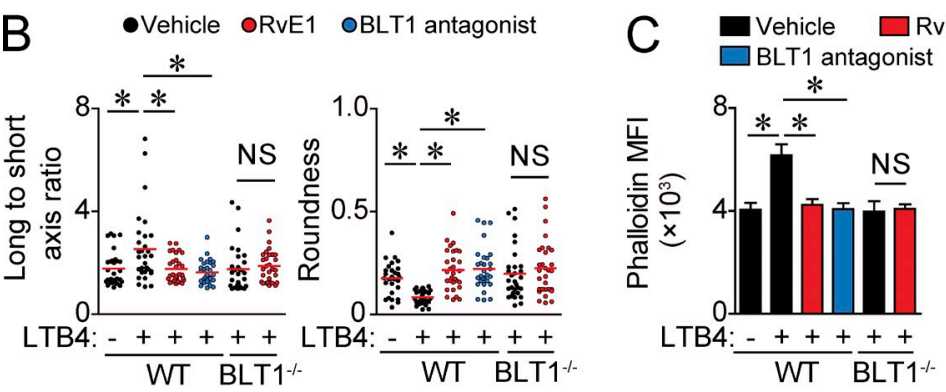

D

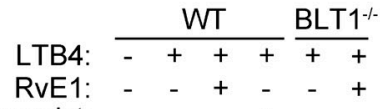

BLT1 antagonist:

GTP-Cdc42 21kD -

Total Cdc42 $21 \mathrm{kD}$

GTP-Rac1 $21 \mathrm{kD}$

Total Rac1 $21 \mathrm{kD}$

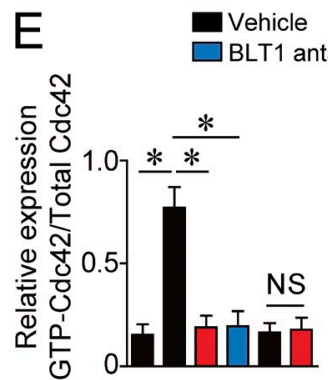

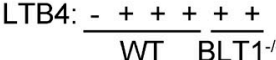
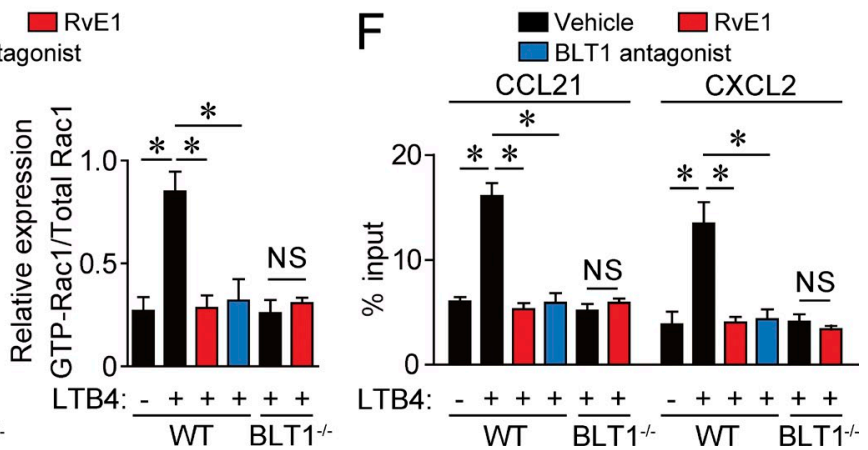

Figure 6. Actin filament reorganization by LTB4-BLT1 signaling in DCs. (A) F-actin staining of DCs. WT and BLT1-deficient BMDCs were incubated on fibronectin-coated coverslips for $30 \mathrm{~min}$ in the presence or absence of $100 \mathrm{nM} \mathrm{LTB4}$. The LTB4-treated cells were pretreated with vehicle, $100 \mathrm{nM}$ RvE1, or $10 \mathrm{nM}$ BLT1 antagonist (U-75302) for $1 \mathrm{~h}$. F-actin was stained with phalloidin (green). The nucleus was stained with DAPI (blue). Bars, $5 \mu \mathrm{m}$. (B) Quantification of the morphological changes (long to short axis ratio and roundness) in BMDCs in A. Each symbol represents an individual cell. Red horizontal lines indicate median values. (C) The MFI of F-actin expression in BMDCs in A. Values of the MFI were evaluated by flow cytometry. (D) Immunoblot analysis for GTP- and total-Cdc42 and GTPand total-Rac1 in WT and BLT1-deficinet BMDCs pretreated with vehicle, RvE1, or a BLT1 antagonist and stimulated with LTB4 for $30 \mathrm{~min}$. (E) Quantification of immunoblot analysis for GTP-Cdc42 and GTP-Rac1 in D $(n=3)$. The intensity of the band of Cdc42 and Rac 1 was measured by densitometry (ImageJ) normalized to the mean total $\mathrm{Cdc} 42$ and Rac1 intensity. (F) Transwell migration assay for DCs. WT or BLT1-deficient BMDCs were pretreated with LTB4, and the numbers of DCs migrated into the lower chamber containing $100 \mathrm{nM}$ CCL21 or $50 \mathrm{nM} \mathrm{CXCL2}$ were measured $5 \mathrm{~h}$ later. The graphs indicate the percentage of migrated DCs to total input DCs. Results are expressed as the mean \pm SEM. All p-values were obtained by Student's $t$ test: ${ }^{*} P<0.05$. All data are representative of six independent experiments with reproducible results.
Furthermore, RvE1 treatment exhibited no additional effects in BLT1-deficient DCs (Fig. 6 F). Therefore, LTB4-BLT1 signaling seems to facilitate DC motility by promoting actin polymerization, which is antagonized by RvE1.

\section{DISCUSSION}

In this study, we revealed that RvE1 down-regulates DC motility in both steady state and inflammatory conditions in the skin and exerts its antiinflammatory effects in CHS. The motility of the three major skin DC subsets is similarly affected by RvE1 and BLT1 deficiency both in the steady state and during inflammation. We propose LTB4-BLT1 signaling blockade as a possible major mechanism through which RvE1 exerts its regulatory effects. In addition, LTB4-BLT1 signaling facilitates cutaneous DC motility by inducing actin polymerization with $\mathrm{Cdc} 42$ and Rac1 activation. Collectively, our results underscore the importance of LTB4-BLT1 signaling on cutaneous DC motility and the subsequent immune response, which is abrogated by RvE1.

Previous studies suggested that the antiinflammatory effect by RvE1 is mediated by modulation of cytokine production by DCs (Arita et al., 2005a; Haworth et al., 2008). In contrast, the significance of DC motility in acquired immunity has been demonstrated (Honda et al., 2013; Natsuaki et al., 2014). Although we could not exclude the possibility that RvE1 modulates cytokine production by cutaneous DCs and affects CHS response, we propose that regulation of DC motility is another possible key mechanism by which RvE1 exerts the antiinflammatory effects in acquired immunity. The effect of RvE1 on DC motility in cutaneous immunity is consistent with a previous observation in the spleen that RvE1 suppresses DC migration induced by the Toxoplasma 
gondii-soluble tachyzoite antigens (Arita et al., 2005a). Here we demonstrated that the attenuated DC migration by RvE1 was observed in WT mice but not in BLT1-deficient mice and that a ChemR23 agonist did not significantly influence DC migration. Our current findings together with the previous study suggest that RvE1 attenuates the cytokine production by DCs and cutaneous DC migration via stimulation with ChemR23 and a blockade of BLT1, respectively.

In this study, we have demonstrated that LTB4-BLT1 signaling promotes actin polymerization in DCs by inducing Cdc42 and Rac1 activation, which was inhibited by RvE1. The aforementioned mechanism may explain the inhibitory mechanism of RvE1 on DC motility and morphological changes in the skin. In fact, BMDCs lacking Rac1 and Rac2, or Cdc42, exhibit round-shaped morphology and do not migrate to dLNs (Benvenuti et al., 2004; Lämmermann et al., 2009). Here we demonstrated that LTB4 was produced by DCs themselves, and its production was further enhanced by DC activation. Therefore, the aforementioned findings suggest that LTB4 produced by DCs themselves facilitates cutaneous DC motility via BLT1 to establish acquired immunity.

We recently reported that dermal DC clusters are essential structures that initiate effector T cell activation and that IL-1 $\alpha$ is a key factor in inducing the clusters (Natsuaki et al., 2014). In the current study, we revealed that LTB4-BLT1 signaling is another important mediator for DC cluster formation. It has been reported that IL-1 induces LTB4 production from neutrophils (Smith et al., 1987) and that IL-1 receptor antagonist down-regulates LTB4 production from monocytes (Conti et al., 1992, 1993). Therefore, IL-1 observed in skin inflammation (Natsuaki et al., 2014) may induce LTB4 production in the skin, which may lead to increased DC motility and subsequent DC cluster formation in the skin.

Collectively, our results newly clarified the regulatory mechanisms of RvE1 in vivo and the effect of LTB4-BLT1 signaling on cutaneous DC motility. RvE1 is an endogenous lipid mediator with strong antiinflammatory effects, and the increase of LTB4 is detected in various inflammatory diseases (Honda and Kabashima, 2014); therefore, RvE1 may lead to the development of novel antiinflammatory drugs to regulate acquired immune responses. In contrast, RvE1 may attenuate the resistance to microorganisms by inhibiting BLT1 signaling. Indeed, LTB4-BLT1 signaling contributes to the exclusion of microorganisms, such as histoplasmosis (Secatto et al., 2014) and cytomegalovirus (Gaudreault and Gosselin, 2007). Therefore, cautious examination of the effect of RvE1 on infection is required for considering further clinical application.

\section{MATERIALS AND METHODS}

Animals. Female C57BL/6 (B6) mice were purchased from Japan SLC. All experiments were conducted on 8- to 12-wk-old mice. BLT1-deficient mice on B6 background were generated as previously described (Terawaki et al., 2005). Kaede transgenic mice on B6 background were generated as previously described (Tomura et al., 2010) and were provided by M. Tomura (Laboratory of Immunology, Faculty of Pharmacy, Osaka Ohtani University,
Tondabayashi, Osaka, Japan). CD11c-YFP mice on B6 background were obtained from the Jackson Laboratory.

Reagents. APC-conjugated anti-CD11c, anti-CD44, and anti-IFN- $\gamma$ mAbs; APC-Cy7-conjugated anti-B220, anti-CD4, and anti-CD11c mAbs; FITCconjugated anti-MHC class II mAb; PB-conjugated anti-CD11c, anti-CD45, and anti-MHC class II mAbs; PE-conjugated anti-CD8, anti-CD62L, and anti-TCR $\beta$ mAbs; PE-Cy7-conjugated anti-CD45 and anti-MHC class II $\mathrm{mAbs}$; and annexin $\mathrm{V}$ and PI were purchased from eBioscience. BLT1 antagonist U-75302 was purchased from Cayman Chemical. A ChemR23 agonist (recombinant murine chemerin) was purchased from R\&D Systems. BLT1 antagonist ONO-4057 was provided by Ono Pharmaceutical Co., Ltd. RvE1 was synthesized as previously described (Ogawa and Kobayashi, 2009).

DNFB-induced CHS model and adoptive transfer. Mice were sensitized through the application of $25 \mu \mathrm{l}$ of $0.5 \%(\mathrm{wt} / \mathrm{vol}$ ) DNFB (Nacalai Tesque) in $4: 1$ acetone/olive oil ( $\mathrm{vol} / \mathrm{vol})$ to their shaved abdomens. They were challenged on both sides of each ear with $20 \mu \mathrm{l}$ of $0.3 \%$ (wt/vol) DNFB $5 \mathrm{~d}$ after sensitization. RvE1 (200 ng/mouse in $200 \mu \mathrm{l}$ of $1.8 \%$ ethanol in PBS) or its vehicle $(200 \mu \mathrm{l}$ of $1.8 \%$ ethanol in PBS) was applied $1 \mathrm{~d}$ before and on the day of sensitization or $5 \mathrm{~d}$ after sensitization via intravenous injection, according to a previous study (Haworth et al., 2008) with some modifications. Ear thickness change was measured for each mouse before and 24 and $48 \mathrm{~h}$ after the challenge using a thickness gauge (Teclok), and the difference was expressed as ear swelling. For adoptive transfer, single-cell suspensions were prepared from axillary dLNs of mice $5 \mathrm{~d}$ after sensitization with $0.5 \%$ DNFB. LN cells from one mouse were injected intravenously into one naive recipient mouse and then challenged with $0.5 \%$ DNFB.

Photoconversion. Photoconversion of the skin was performed as previously described (Tomura et al., 2010). In brief, Kaede transgenic mice were anesthetized, shaved on the abdomen, and exposed to violet light at $95 \mathrm{~mW} / \mathrm{cm}^{2}$ with a 436-nm bandpass filter using Spot UV curing equipment for $10 \mathrm{~min}$ (SP500; USHIO).

Immunostaining. Immunostaining for BMDCs was performed as reported previously (Tanizaki et al., 2010), with some modification. In brief, BMDCs were plated on coverslips coated with $10 \mu \mathrm{g} / \mathrm{ml}$ fibronectin (Sigma-Aldrich) for $16 \mathrm{~h}$. The cells were fixed for $15 \mathrm{~min}$ with $3.7 \%$ formalin (Wako Pure Chemical Industries) and permeabilized with $0.1 \%$ Triton-X (Sigma-Aldrich) in PBS for $7 \mathrm{~min}$ at room temperature. Next, slides were incubated with Alexa Fluor 488-conjugated phalloidin (Invitrogen) at room temperature for $1 \mathrm{~h}$. The slides were mounted in ProLong Gold Antifade reagent (Invitrogen), and fluorescence images were obtained using a BIOREVO BZ-9000 system (Keyence). The data were further processed using ImageJ software (National Institutes of Health).

For whole-mount staining, the ears were split into dorsal and ventral halves and then incubated for $30 \mathrm{~min}$ at $37^{\circ} \mathrm{C}$ with $0.5 \mathrm{M}$ ammonium thiocyanate. Next, the dermal sheets were separated and fixed in acetone for $10 \mathrm{~min}$ at $-20^{\circ} \mathrm{C}$. After treatment with Image-iT FX Signal Enhancer (Invitrogen), the sheets were incubated with Ab to mouse MHC class II (eBioscience) followed by incubation with $\mathrm{Ab}$ to rat $\operatorname{IgG}$ conjugated to Alexa Fluor 488 (Invitrogen). The slides were mounted with a ProLong Antifade kit and were observed using a fluorescence microscope (BIOREVO BZ-9000). The number and the size of DC clusters were evaluated in 10 fields of $1 \mathrm{~mm}^{2}$ per ear and were assigned scores according to the previously described criteria (Natsuaki et al., 2014). Histological assessment was conducted blindly by two different dermatopathologists.

BMDC culture. For BMDC culture, $5 \times 10^{6} \mathrm{BM}$ cells generated from WT and BLT1-deficient mice were cultured in $10 \mathrm{ml}$ cRPMI (RPMI 1640; Sigma-Aldrich), containing 10\% heat-inactivated FCS (Invitrogen), $50 \mu \mathrm{M}$ 2-mercaptoethanol, $2 \mathrm{mM}$ L-glutamine, $25 \mathrm{mM} \mathrm{N}$-2-hydroxyethylpiperazine$N^{\prime}$-2-ethanesulfonic acid, $1 \mathrm{mM}$ nonessential amino acids, $1 \mathrm{mM}$ sodium pyruvate, $100 \mathrm{U} / \mathrm{ml}$ penicillin, and $100 \mu \mathrm{g} / \mathrm{ml}$ streptomycin supplemented with $10 \mathrm{ng} / \mathrm{ml}$ of recombinant murine GM-CSF (PeproTech) for 5-7 d. 
Flow cytometry. Single-cell suspensions from skin dLNs were prepared $5 \mathrm{~d}$ after sensitization and stained with the indicated Abs. For the preparation of single-cell suspensions from skin, the ears were split into dorsal and ventral halves, and the cartilage was removed. The ear skin was incubated for $1 \mathrm{~h}$ in cRPMI containing $2 \mathrm{mg} / \mathrm{ml}$ collagenase II (Worthington Biochemical Corporation) and $100 \mu \mathrm{g} / \mathrm{ml}$ DNase I (Sigma-Aldrich). The cell suspensions were filtered using a $40-\mu \mathrm{m}$ cell strainer and stained with the indicated Abs. These cells were subjected to a flow cytometry (Fortessa; BD), and the data were analyzed with FlowJo software (Tree Star).

FITC-induced cutaneous DC migration. The shaved abdomens of the mice were painted with $200 \mu \mathrm{l}$ of $1 \%$ (wt/vol) FITC (Sigma-Aldrich) dissolved in a 1:1 (vol/vol) acetone/dibutyl phthalate mixture. RvE1 (200 ng/mouse in $200 \mu \mathrm{l}$ of $1.8 \%$ ethanol in PBS) or its vehicle (200 $\mu \mathrm{l}$ of $1.8 \%$ ethanol in PBS) was applied intravenously $30 \mathrm{~min}$ before and $1 \mathrm{~d}$ after FITC application. Samples of axillary LNs were taken for flow cytometric analysis $48 \mathrm{~h}$ after FITC application. The cutaneous DCs migrating into the axillary dLNs were then analyzed by flow cytometry using Flow-Count Fluorospheres (Beckman Coulter).

Transmigration assay. Single-cell suspensions from BMDCs were incubated for 30 min with TNF (R\&D Systems) or LTB4 (Cayman Chemical) and tested for transmigration across uncoated $5-\mu \mathrm{m}$ transwell filters (Corning) to $100 \mathrm{nM}$ CCL21 (R\&D Systems), $50 \mathrm{nM}$ CXCL2 (R\&D Systems), or medium for $5 \mathrm{~h}$. Migrating cells were subjected to flow cytometry. RPMI 1640 with $0.5 \%$ fatty acid-free BSA (EMD Millipore) was used as the culture medium.

Two-photon microscopy. Two-photon imaging was performed as previously described (Natsuaki et al., 2014), with some modifications. In brief, mice were anesthetized with isoflurane and were positioned on the heating plate on the stage of a two-photon microscope (IX-81; Olympus), with their earlobes fixed beneath coverslips with a single drop of immersion oil. Stacks of three images, spaced $4 \mu \mathrm{m}$ apart, were acquired every $1 \mathrm{~min}$ for the indicated period. Videos were further processed using Imaris software (Bitplane). To visualize cutaneous DCs, CD11c-YFP transgenic mice, in which CD11cpositive cells express cytoplasmic YFP, were used (Lindquist et al., 2004). For the evaluation of cutaneous DC motility, we randomly selected 100 DCs in the observation field and tracked the DC movement in the same time spans (30 min) using Imaris software.

Western blotting. Cdc42 and Rac1 activity assays were performed according to the manufacturer's protocol. In brief, BMDCs were lysed directly in their $10-\mathrm{cm}$ plates with ice-cold lysis buffer. Lysates were then incubated at $4^{\circ} \mathrm{C}$ with $10 \mu \mathrm{g}$ PAK-PBD beads (Cytoskeleton, Inc.). Proteins from the total cell lysate, as well as the bead pellets, were separated by $10 \%$ SDSPAGE gel, transferred to a nitrocellulose membrane, and blotted for the appropriate GTPase using a mouse monoclonal anti-Cdc42 Ab (Cytoskeleton, Inc.) or a mouse monoclonal anti-Rac1 $\mathrm{Ab}$ (Cytoskeleton, Inc.).

Lymphocyte proliferation assay. Single-cell suspensions were prepared from axillary dLNs of mice $5 \mathrm{~d}$ after sensitization with DNFB. One million LN cells were cultured with or without the different concentrations of dinitrobenzene sulfonic acid (DNBS; 50 and $100 \mu \mathrm{g} / \mathrm{ml}$; Alfa Aesar) for $72 \mathrm{~h}$, pulsed with $0.5 \mu \mathrm{Ci}\left[{ }^{3} \mathrm{H}\right]$ thymidine for the last $24 \mathrm{~h}$, and subjected to liquid scintillation counting. For the measurement of cytokine production, culture supernatants were collected $48 \mathrm{~h}$ after incubation. The amount of IFN- $\gamma$ was measured by ELISA (BD) according to the manufacturer's instructions.

ELISA. BMDCs $\left(10^{6} /\right.$ well) were stimulated with or without $100 \mathrm{ng} / \mathrm{ml}$ TNF for $12 \mathrm{~h}$. For measurement of LTB4 production, culture supernatants were collected $12 \mathrm{~h}$ after incubation. The LTB4 concentration of culture supernatants was measured by ELISA (Cayman Chemical) according to the manufacturer's instructions.

Generation of BM chimera mice. To generate mixed BM chimera mice, recipient WT CD45.2-positive B6 mice underwent 9 Gy total body irradiation and received mixed BM single-cell suspensions from congenic WT CD45.1-positive mice and BLT1-deficient CD45.2-positive mice with 1:1 ratio $\left(2 \times 10^{6}\right.$ cells from each strain $)$ intravenously through the tail vein. The chimeric mice were used for the indicated experiment 2 mo after the reconstitution.

Statistical analysis. All statistical analyses were performed using Prism 4.0 (GraphPad Software). The Student's $t$ test or Welch's $t$ test was used to calculate statistical differences. All p-values $<0.05$ were considered statistically significant.

Study approval. All experimental procedures were approved by the Institutional Animal Care and Use Committee of Kyoto University Graduate School of Medicine.

Online supplemental material. Videos 1-4 show DC migration in steady state skin in vehicle-treated (Video 1), RvE1-treated (Video 2), BLT1 antagonist-treated (Video 3), and RvE1- plus BLT1 antagonist-treated (Video 4) CD11c-YFP mice.Videos 5-8 show DC migration in inflammatory state in vehicle-treated (Video 5), RvE1-treated (Video 6), BLT1 antagonisttreated (Video 7), and RvE1- plus BLT1 antagonist-treated (Video 8) CD11c-YFP mice. Online supplemental material is available at http://www .jem.org/cgi/content/full/jem.20150381/DC1.

We thank H. Kitajima (Department of Work Systems and Health, Institute of Industrial Ecological Sciences, University of Occupational and Environmental Health) for advising on the statistical analyses.

This work was supported in part by Grants-in-Aid for Scientific Research from the Ministry of Education, Culture, Sports, Science and Technology and the Ministry of Health, Labour and Welfare of Japan (to K. Kabashima); Precursory Research for Embryonic Science and Technology, Japan Agency for Medical Research and Development, and Japan Agency for Medical Research and Development (to K. Kabashima); and the Japanese Society for Investigative Dermatology's Fellowship SHISEIDO Award (to T. Honda).

The authors declare no competing financial interests.

Submitted: 3 March 2015

Accepted: 1 September 2015

\section{REFERENCES}

Ando, R., H. Hama, M.Yamamoto-Hino, H. Mizuno, and A. Miyawaki. 2002. An optical marker based on the UV-induced green-to-red photoconversion of a fluorescent protein. Proc. Natl.Acad. Sci. USA. 99:12651-12656. http://dx.doi.org/10.1073/pnas.202320599

Arita, M., F. Bianchini, J. Aliberti, A. Sher, N. Chiang, S. Hong, R. Yang, N.A. Petasis, and C.N.Serhan.2005a. Stereochemical assignment, antiinflammatory properties, and receptor for the omega-3 lipid mediator resolvin E1. J. Exp. Med. 201:713-722. http://dx.doi.org/10.1084/jem.20042031

Arita, M., M.Yoshida, S. Hong, E. Tjonahen, J.N. Glickman, N.A. Petasis, R.S. Blumberg, and C.N. Serhan. 2005b. Resolvin E1, an endogenous lipid mediator derived from omega- 3 eicosapentaenoic acid, protects against 2,4,6-trinitrobenzene sulfonic acid-induced colitis. Proc. Natl. Acad. Sci. USA. 102:7671-7676. http://dx.doi.org/10.1073/pnas.0409271102

Arita, M., T. Ohira, Y.P. Sun, S. Elangovan, N. Chiang, and C.N. Serhan. 2007. Resolvin E1 selectively interacts with leukotriene B4 receptor BLT1 and ChemR23 to regulate inflammation. J. Immunol. 178:39123917. http://dx.doi.org/10.4049/jimmunol.178.6.3912

Benvenuti, F., S. Hugues, M. Walmsley, S. Ruf, L. Fetler, M. Popoff, V.L. Tybulewicz, and S. Amigorena. 2004. Requirement of Rac1 and Rac2 expression by mature dendritic cells for $\mathrm{T}$ cell priming. Science. 305:1150-1153. http://dx.doi.org/10.1126/science.1099159

Conti, P., M.R. Panara, R.C. Barbacane, F.C. Placido, M. Bongrazio, M. Reale, R.A. Dempsey, and S. Fiore. 1992. Blocking the interleukin-1 receptor inhibits leukotriene B4 and prostaglandin E2 generation in human monocyte cultures. Cell. Immunol. 145:199-209. http://dx.doi.org/ 10.1016/0008-8749(92)90323-H

Conti, P., M.R. Panara, R.C. Barbacane, M. Bongrazio, R.A. Dempsey, and M. Reale. 1993. Human recombinant IL-1 receptor antagonist (IL-1Ra) 
inhibits leukotriene B4 generation from human monocyte suspensions stimulated by lipopolysaccharide (LPS). Clin. Exp. Immunol. 91:526531. http://dx.doi.org/10.1111/j.1365-2249.1993.tb05936.x

Dyerberg, J., H.O. Bang, E. Stoffersen, S. Moncada, and J.R. Vane. 1978 Eicosapentaenoic acid and prevention of thrombosis and atherosclerosis? Lancet. 312:117-119. http://dx.doi.org/10.1016/S0140-6736(78)91505-2

Edwards, D.C., L.C. Sanders, G.M. Bokoch, and G.N. Gill. 1999. Activation of LIM-kinase by Pak1 couples Rac/Cdc42 GTPase signalling to actin cytoskeletal dynamics. Nat. Cell Biol. 1:253-259. http:// dx.doi.org/10.1038/12963

Förster, R., A. Schubel, D. Breitfeld, E. Kremmer, I. Renner-Müller, E. Wolf, and M. Lipp. 1999. CCR7 coordinates the primary immune response by establishing functional microenvironments in secondary lymphoid organs. Cell. 99:23-33. http://dx.doi.org/10.1016/S0092-8674(00)80059-8

Gaudreault, E., and J. Gosselin. 2007. Leukotriene B4-mediated release of antimicrobial peptides against cytomegalovirus is BLT1 dependent. Viral Immunol. 20:407-420. http://dx.doi.org/10.1089/vim.2006.0099

Haas-Stapleton, E.J., Y. Lu, S. Hong, M. Arita, S. Favoreto, S. Nigam, C.N. Serhan, and N. Agabian. 2007. Candida albicans modulates host defense by biosynthesizing the pro-resolving mediator resolvin E1. PLoS ONE. 2:e1316. http://dx.doi.org/10.1371/journal.pone.0001316

Haworth, O., M. Cernadas, R. Yang, C.N. Serhan, and B.D. Levy. 2008. Resolvin E1 regulates interleukin 23, interferon- $\gamma$ and lipoxin $A_{4}$ to promote the resolution of allergic airway inflammation. Nat. Immunol. 9:873-879. http://dx.doi.org/10.1038/ni.1627

Honda, T., and K. Kabashima. 2014. Leukotrienes as key mediators and amplifiers in allergic inflammation: insights from the bench and clinic. Exp. Dermatol. 23:95-96. http://dx.doi.org/10.1111/exd.12282

Honda, T., S. Nakajima, G. Egawa, K. Ogasawara, B. Malissen, Y. Miyachi, and K. Kabashima. 2010. Compensatory role of Langerhans cells and langerin-positive dermal dendritic cells in the sensitization phase of murine contact hypersensitivity. J. Allergy Clin. Immunol. 125:1154-1156. http://dx.doi.org/10.1016/j.jaci.2009.12.005

Honda, T., G. Egawa, S. Grabbe, and K. Kabashima. 2013. Update of immune events in the murine contact hypersensitivity model: toward the understanding of allergic contact dermatitis. J. Invest. Dermatol. 133:303315. http://dx.doi.org/10.1038/jid.2012.284

Honda, T., J.G. Egen, T. Lämmermann, W. Kastenmüller, P. Torabi-Parizi, and R.N. Germain. 2014. Tuning of antigen sensitivity by T cell receptor-dependent negative feedback controls $\mathrm{T}$ cell effector function in inflamed tissues. Immunity. 40:235-247. http://dx.doi.org/10.1016/ j.immuni.2013.11.017

Horrobin, D.F. 1987. Low prevalences of coronary heart disease (CHD), psoriasis, asthma and rheumatoid arthritis in Eskimos: are they caused by high dietary intake of eicosapentaenoic acid (EPA), a genetic variation of essential fatty acid (EFA) metabolism or a combination of both? Med Hypotheses. 22:421-428. http://dx.doi.org/10.1016/0306-9877(87)90037-5

Lämmermann, T., and R.N. Germain. 2014. The multiple faces of leukocyte interstitial migration. Semin. Immunopathol. 36:227-251. http:// dx.doi.org/10.1007/s00281-014-0418-8

Lämmermann, T., J. Renkawitz, X. Wu, K. Hirsch, C. Brakebusch, and M. Sixt. 2009. Cdc42-dependent leading edge coordination is essential for interstitial dendritic cell migration. Blood. 113:5703-5710. http:// dx.doi.org/10.1182/blood-2008-11-191882

Lin, Y., X. Yang, W. Yue, X. Xu, B. Li, L. Zou, and R. He. 2014. Chemerin aggravates DSS-induced colitis by suppressing M2 macrophage polarization. Cell. Mol. Immunol. 11:355-366. http://dx.doi.org/10 $.1038 / \mathrm{cmi} .2014 .15$

Lindquist, R.L., G. Shakhar, D. Dudziak, H. Wardemann, T. Eisenreich, M.L. Dustin, and M.C. Nussenzweig. 2004.Visualizing dendritic cell networks in vivo. Nat. Immunol. 5:1243-1250. http://dx.doi.org/10.1038/ni1139

Luangsay, S., V. Wittamer, B. Bondue, O. De Henau, L. Rouger, M. Brait, J.D. Franssen, P. de Nadai, F. Huaux, and M. Parmentier. 2009. Mouse ChemR23 is expressed in dendritic cell subsets and macrophages, and mediates an anti-inflammatory activity of chemerin in a lung disease model. J. Immunol. 183:6489-6499. http://dx.doi.org/10 $.4049 /$ jimmunol.0901037

Mori, T., K. Kabashima, R. Yoshiki, K. Sugita, N. Shiraishi, A. Onoue, E. Kuroda, M. Kobayashi, U. Yamashita, and Y. Tokura. 2008. Cutaneous hypersensitivities to hapten are controlled by IFN- $\gamma$-upregulated keratinocyte Th1 chemokines and IFN- $\gamma$-downregulated langerhans cell Th2 chemokines. J. Invest. Dermatol. 128:1719-1727. http://dx.doi.org/ $10.1038 / \mathrm{jid} .2008 .5$

Natsuaki, Y., G. Egawa, S. Nakamizo, S. Ono, S. Hanakawa, T. Okada, N. Kusuba, A. Otsuka, A. Kitoh, T. Honda, et al. 2014. Perivascular leukocyte clusters are essential for efficient activation of effector T cells in the skin. Nat. Immunol. 15:1064-1069. http://dx.doi.org/10.1038/ni.2992

Ogawa, N., and Y. Kobayashi. 2009. Total synthesis of resolving E1. Tetrahedron Lett. 50:6079-6082. http://dx.doi.org/10.1016/j.tetlet.2009.08.061

Secatto, A., E.M. Soares, G.A. Locachevic, P.A. Assis, F.W. Paula-Silva, C.H. Serezani, A.I. de Medeiros, and L.H. Faccioli. 2014. The leukotriene $\mathrm{B}_{4} / \mathrm{BLT}_{1}$ axis is a key determinant in susceptibility and resistance to histoplasmosis. PLoS ONE. 9:e85083. http://dx.doi.org/10.1371/journal .pone. 0085083

Serhan, C.N., N. Chiang, and T.E. Van Dyke. 2008. Resolving inflammation: dual anti-inflammatory and pro-resolution lipid mediators. Nat. Rev. Immunol. 8:349-361. http://dx.doi.org/10.1038/nri2294

Smith, R.J., D.E. Epps, J.M. Justen, L.M. Sam, M.A. Wynalda, F.A. Fitzpatrick, and F.S. Yein. 1987. Human neutrophil activation with interleukin-1. A role for intracellular calcium and arachidonic acid lipoxygenation. Biochem. Pharmacol. 36:3851-3858. http://dx.doi.org/ 10.1016/0006-2952(87)90449-7

Tanizaki, H., G. Egawa, K. Inaba, T. Honda, S. Nakajima, C.S. Moniaga, A Otsuka, T. Ishizaki, M. Tomura, T. Watanabe, et al. 2010. Rho-mDia1 pathway is required for adhesion, migration, and T-cell stimulation in dendritic cells. Blood. 116:5875-5884. http://dx.doi.org/10.1182/blood2010-01-264150

Terawaki, K., T. Yokomizo, T. Nagase, A. Toda, M. Taniguchi, K. Hashizume, T. Yagi, and T. Shimizu. 2005. Absence of leukotriene B4 receptor 1 confers resistance to airway hyperresponsiveness and Th2-type immune responses. J. Immunol. 175:4217-4225. http://dx.doi.org/10 .4049/jimmunol.175.7.4217

Tomura, M., T. Honda, H. Tanizaki, A. Otsuka, G. Egawa, Y. Tokura, H. Waldmann, S. Hori, J.G. Cyster, T. Watanabe, et al. 2010. Activated regulatory $\mathrm{T}$ cells are the major $\mathrm{T}$ cell type emigrating from the skin during a cutaneous immune response in mice. J. Clin. Invest. 120:883893. http://dx.doi.org/10.1172/JCI40926

Tull, S.P., C.M.Yates, B.H. Maskrey,V.B. O’Donnell, J. Madden, R.F. Grimble, P.C. Calder, G.B. Nash, and G.E. Rainger. 2009. Omega-3 Fatty acids and inflammation: novel interactions reveal a new step in neutrophil recruitment. PLoS Biol. 7:e1000177. http://dx.doi.org/10.1371/journal .pbio. 1000177 